\title{
O ENSINO DE LITERATURA E A GASTRONOMIA EM CENA: UMA PROPOSTA PARA A FORMAÇÃO DOCENTE
}

\author{
Letícia Queiroz de Carvalho' \\ Murilo Góes Martins ${ }^{2}$
}

\begin{abstract}
Resumo: O presente artigo busca um diálogo entre alguns pressupostos teóricos da gastronomia e o ensino de literatura na perspectiva da formação do professor da área de Letras. Teoricamente, pretendemos cotejar os saberes culturais da alimentação manifestados em textos representativos da literatura e ensino com os postulados de Bakhtin e o Círculo, para sustentar a nossa hipótese investigativa de que é possível suscitar, nos professores de Português, o estímulo a leituras críticas do texto literário pelos signos da alimentação nele presentes. Em nossa interlocução teórica, traremos também considerações atinentes ao conceito de gastronomia, formalizados por BrillatSavarin e as concepções barthesianas relacionadas ao prazer do texto. Tal diálogo aponta o potencial da convergência teórica entre literatura e gastronomia nos processos de formação docente, por meio de uma proposição prática de leitura para professores.
\end{abstract}

Palavras-chave: Ensino de literatura; gastronomia; formação docente.

\section{The teaching of Literature and Gastronomy on the scene: a proposal for teacher education}

\begin{abstract}
This article seeks a dialogue between some theoretical assumptions of gastronomy and the teaching of literature from the perspective of the formation of the teacher in the area of Letters. Theoretically, we intend to compare the cultural knowledge of food manifested in texts representative of literature and teaching with the postulates of Bakhtin and the Circle, to support our investigative hypothesis that it is possible to estimulate, in teachers of Portuguese, the stimulus to critical readings of the literary text by the signs of feeding present in it. In our theoretical dialogue, we will also bring considerations regarding the concept of gastronomy, formalized by Brillat-Savarin and the Barthesian conceptions related to the pleasure of the text. This dialogue points to the potential of theoretical convergence between literature and gastronomy in the processes of teacher education, through a practical proposition of reading for teachers.
\end{abstract}

Keywords: Literature teaching; gastronomy; teacher training.

Instituto Federal do Espírito Santo (leticia.carvalho@ifes.edu.br)

Instituto Federal do Espírito Santo (murilo.goes@hotmail.com)

$$
\begin{array}{lll}
\text { v. } 22 \text { n. } 52 \text { p. } 6-25 \quad \text { out./dez. } 2020
\end{array}
$$




\section{INTRODUÇÃO}

Ler pode ser uma fonte de alegria. Pode ser. Nem sempre é. Livros são iguais à comida. Há os pratos refinados, como o cailles au sarcophage, especialidade de Babette, que começam por dar prazer ao corpo e terminam por dar alegria à alma. $\mathrm{E}$ há as gororobas, malcozidas, empelotadas, salgadas, engorduradas, que além de produzir vômito e diarreia no corpo produzem perturbações semelhantes na alma. Assim também os livros. Ler é uma virtude gastronômica: requer uma educação da sensibilidade, uma arte de discriminar os gostos. $\mathrm{O}$ chef prova os pratos que prepara antes de servi-los. O leitor cuidadoso, de forma semelhante, prova um canapé do livro antes de se entregar à leitura (ALVES, 2007, p. 49).

O ato de alimentar-se e o de ler são dotados de simbolismos culturais, já que, em ambos, podemos observar algumas dimensões da vida social. Assim, comida e literatura, a todo instante, apropriam-se e falam de ideias que circulam em torno de simbologias; enquanto referenciais dinâmicos - e, de certa forma, reconhecidos entre distintos grupos - proporcionaram possibilidades para pensar como é se movimentar entre conceitos sociais que nem sempre oferecem fronteiras evidentes: etnia, reconhecimento, exclusão, distinção, classe, geração, gênero etc. estão presentes entre as constituições alimentares e os registros literários. Na mesma medida em que estabelecem marcadores de diferença, pratos e livros são também capazes de fortalecer a construção de identidades por evocarem emoções, memórias, tradições e histórias.

Compreendendo a potencialidade de estudos sociais concernentes à comida e à leitura, defendemos que o ensino de literatura deve ser desenvolvido em prol de respeitar os diferentes gostos e de despertar, nos leitores, um apetite cultural; é preciso, para isso, articular uma atuação docente capaz de ressignificar as dinâmicas com leituras literárias em sala de aula. Nesse processo, algumas receitas praticadas nas aulas de Língua Portuguesa precisam ser observadas, em prol de potencializar novos sabores à aquisição de saberes e também de prazeres.

Carnavalizar o ensino de literatura apresenta-se como alternativa à necessidade de repensar práticas docentes excessivamente dogmáticas e pouco 
dialógicas. O carnaval é um espetáculo ritualístico que funde ações e gestos elaborando uma linguagem própria; a carnavalização adere a essa visão vasta e popular de carnaval que se opõe ao sério, ao individual, ao medo, à discriminação, ao dogmático. Embora no século XXI ainda seja muito explorado pelos estudos da crítica literária, o conceito de carnavalização não se popularizou em outras aplicações sociais, entre as quais buscamos recortar uma compreensão mais ampla de como tal concepção bakhtiniana pode ajudar em busca de um ensino mais prazeroso de literatura.

Considerando que este artigo tem como objetivo apresentar as relações possíveis entre gastronomia e o ensino de literatura, para fundamentar práticas de leitura em processos formativos com os docentes na área de Letras, o presente texto expõe e analisa uma possibilidade de formação continuada à luz dessas interações conceituais, por meio do diálogo entre a perspectiva bakhtiniana atinente à cultura popular, ao riso libertador, aos princípios nucleares da literatura carnavalizada e alguns pressupostos teóricos da gastronomia e da literatura, a partir das relações entre tais campos do conhecimento.

Pretendemos também realizar uma interlocução com as concepções barthesianas relacionadas ao prazer do texto para sustentar a nossa hipótese investigativa de que é possível suscitar, em formações docentes, o estímulo a leituras críticas do texto literário pelos signos da alimentação nele presentes. Para contribuir, conceitualmente, com as análises de categorias relacionadas à gastronomia, dialogaremos também com os estudos concernentes ao conceito de gastronomia, formalizados por Brillat-Savarin. Esperamos, com tal diálogo, compreender o potencial da literatura como produção artística desveladora de uma realidade cultural alinhada ao universo da gastronomia, de modo a potencializar debates e diálogos no processo de formação docente, estimulando a leitura crítica de textos literários como prática em encontros formativos da área de Letras.

\section{LEITURA E ALIMENTAÇÃO: SABORES EM CENA}

Comer é, primeiro, um ato biológico, indispensável para a manutenção de vida, embora seja antecedido por ações como respirar e beber água. Contudo, entender "como" se come - onde e com quem, quando e o quê - requer uma análise voltada aos contextos de interação do homem com sua cultura, ora com 
mais força, ora com menos, mas que se alternam para constituir o comer e a cozinha.

Para Santos (2005), os estudos sobre a comida e a alimentação alcançam interesse nas Ciências Humanas exatamente a partir do entendimento de que a formação do gosto alimentar constitui uma categoria histórica, pois os padrões de permanência e de mudança dos hábitos e das práticas alimentares têm referências na própria dinâmica social. Enquanto alimentar-se é um ato nutricional, comer tal como ler - é um ato social, pois, em sua politização, constitui atitudes ligadas aos usos, costumes, protocolos, condutas e situações.

Reconhecer a alimentação e a leitura enquanto práticas representativas de atos sociais exige considerá-las como manifestações que projetam valores humanos diversificados na socialização entre sujeitos. Nessa perspectiva de defesa, compreendemos que a leitura representa um processo de interação social, pois o ato de ler um texto, por exemplo, não desenvolve significado exclusivamente por si mesmo: o seu sentido é construído na relação entre os elementos envolvidos nesse processo.

Sabemos que a socialização é um processo fundamental não apenas para integração do indivíduo na sua sociedade, mas também para a continuidade ou para a reconstrução dos sistemas sociais; tanto a alimentação quanto a leitura literária, nesse contexto, representam dinâmicas de expressiva potencialidade para significação do mundo e para a continuidade ou reformulação dos sistemas que buscam estruturar, uma vez que ambos projetam subjetividades favoráveis à interação entre o âmbito de valores individuais e o de valores coletivos, determinando, pois, uma articulação que propicia socializações.

A literatura, compreendemos, vislumbra potencial ainda maior nessa perspectiva de socialização, uma vez que permite o registro de notações diversificadas, relacionadas aos valores coletivos. Ora, dialogar acerca da leitura de textos literários é valorizar a análise crítica a respeito de todos os simbolismos neles materializados, uma vez que todos colaboram em permitir a compreensão do leitor em torno das realidades sociais ali constituídas. Não raro, por exemplo, a alimentação é projetada nos textos literários como elemento de representação social nos enredos com ela constituídos. Nossos esforços de pesquisa pretendem valorizar a representatividade das leituras críticas potencializadas pelos simbolismos da alimentação nos textos literários. 
Jean Anthelme Brillat-Savarin foi um dos mais famosos epicuristas e gastrônomos franceses de todos os tempos. Mesmo no século XVIII - período de intensos conflitos ideológicos - Savarin vislumbrava um contexto histórico extremamente favorável para o desenvolvimento da Gastronomia como ciência, entendida como um conjunto de conhecimentos racionais com reflexões filosóficas sobre a nutrição humana. Sua obra A Fisiologia do Gosto, escrita em 1825, trata do homem e da comida e se constitui como produção de gastronomia; nela, o autor apresenta a seguinte definição: "A gastronomia é o conhecimento fundamentado de tudo o que se refere ao homem, na medida em que ele se alimenta” (SAVARIN, 1995, p.25).

A gastronomia é um fator cultural tão evidentemente arraigado no ser humano que, também segundo Massimo Montanari (2009), ela pode ser comparada à própria linguagem, servindo até mesmo como veículo de comunicação:

A cozinha tem sido equiparada à linguagem: como esta, possui vocábulos (os produtos, os ingredientes), que são organizados segundo regras de gramática (as receitas, que dão sentindo aos ingredientes, transformando-os em alimentos), de sintaxe (o cardápio, isto é, a ordem dos pratos) e de retórica (os comportamentos do convívio). A analogia não funciona apenas no plano técnicoestrutural, mas também para valores simbólicos dos quais ambos os sistemas são portadores. Exatamente como a linguagem, a cozinha contém e expressa a cultura de quem a pratica, é depositária das tradições e das identidades de grupo. Constitui, assim, um extraordinário veículo de autorrepresentação e de comunicação (...). Bem mais do que a palavra, a comida auxilia na intermediação entre culturas diferentes, abrindo sistemas culinários a todas as formas de invenções, cruzamentos e contaminações (MONTANARI, 2009, p. 11).

Massimo Montanari é um estudioso italiano da gastronomia no século XXI. Em suas pesquisas, entende que os simbolismos socioculturais perpetrados pela comida permitem estruturar os estudos sobre a alimentação pela ótica da gastronomia. Tal como Montanari é leitor e crítico dos estudos de Brillat-Savarin na Europa, Carlos Alberto Dória é, atualmente, a maior expressão dos estudos relacionados à Sociologia da Alimentação, em solos brasileiros. Já em visão atualizada de pesquisas sobre práticas alimentares, Dória (2006) explica a diferença entre dois conceitos comuns aos estudos relacionados à alimentação: 
A culinária diz respeito aos procedimentos (dos rituais aos técnicos e tecnológicos) que visam adequar a natureza à alimentação humana. Ela é a matéria básica da gastronomia, que é o conjunto de saberes sobre a construção do prazer ao comer. A primeira é uma disciplina prática, com seus métodos, técnicas e gestual; a segunda está organizada no plano do discurso, como ocupação do espírito (DÓRIA, 2006, p. 16-17).

Nessa perspectiva, enquanto a culinária se destina às preparações dos pratos, a gastronomia vai além disso e tem como foco de leitura o comer e as sensações socioculturais a ele relacionadas; ou seja, enquanto a culinária diz respeito à produção de pratos, a gastronomia lança luz sobre seu modo de consumo. Essa consciência acerca da possibilidade de estudar os modos de consumo da alimentação - e os seus respectivos simbolismos - corrobora para a exploração de novas leituras das representações sociais ligadas à temática. Enquanto docente de língua portuguesa, por exemplo, as produções artísticas escritas abriram-me o apetite para os valores simbólicos que permeiam os saberes e sabores da alimentação. Que leituras poderiam ser feitas à personagem Dona Flor no momento em que foi caracterizada enquanto professora de culinária, na narrativa de Jorge Amado? Por que a culinária regional foi tão explorada em escritos de autores da cultura popular? Por que, nos escritos de Monteiro Lobato, Tia Anastácia era a personagem quem desenvolvia deliciosas receitas, mas a fama social de cozinheira recaiu à Dona Benta?

Explorar as representações sociais relacionadas à alimentação no texto literário é, pois, uma forma de cotejar a dinâmica do pensamento coletivo, uma vez que tais se apresentam como uma maneira de interpretar e pensar certa realidade. Entretanto, em prol de estimular leituras mais críticas de produções literárias em sala de aula, faz-se necessária uma atuação docente que favoreça esse incentivo. O pensador e semiólogo francês Roland Barthes, em seu livro Aula (uma palestra proferida ao assumir o cargo de professor no Collège de France, em 1977) explica que a literatura deve ser entendida como disciplina que, por seus múltiplos olhares, envolve uma diversidade de saberes e de áreas do conhecimento: "[...] essa trapaça salutar, essa esquiva, esse logro magnífico que permite ouvir a língua fora do poder, no esplendor de uma revolução permanente da linguagem, eu a chamo, quanto a mim: literatura.” (BARTHES, 1992, p.08).

Defensor da interdisciplinaridade, Barthes acredita que o texto e, em particular, o texto literário, manifesta a energia sígnica, resultante de uma pesquisa interdisciplinar. A interdisciplinaridade questiona a pureza do saber único e 
absoluto; assim, agir interdisciplinarmente significa estudar os saberes de forma humana. Na prática, a perspectiva interdisciplinar representa uma possibilidade de negociação de pontos de vista, de diálogo e de interação entre disciplinas.

Por meio dessa lógica é que no mesmo texto Barthes aponta para o fato de as palavras "saber" e "sabor" terem, em latim, a mesma etimologia, pois é o gosto das palavras que faz o saber profundo e fecundo. Com esse raciocínio, Barthes sugere que a escritura se encontra em toda parte onde as palavras ganham sabor. Assim, todo o texto barthesiano pode ser corpus de uma leitura sob o signo da intertextualidade, na medida em que o semiólogo articula saberes em torno do desejo do saber-sabor, sem dicotomia de fronteiras.

Com a máxima de "saber com sabor", procuramos, além da liberdade crítica, o possível diálogo entre o prazer promovido pelo apetite à comida como caminho também potencial para originar prazer promovido pelo leitor ao texto, inclusive pelos signos da alimentação nele reunidos. Na medida em que comer é culturalmente também um símbolo que remete ao hedonismo, produzir sentidos a partir de signos alimentares em textos literários pode, do mesmo modo, ser uma prática prazerosa, além de crítica. Faz-se necessário, para tal, desenvolver um olhar diferente a respeito do ensino de literatura na educação básica; um tipo de ensino que renuncie qualquer pretensão de leitura sistemática, baseada em verdades linguísticas, históricas ou sociológicas.

Nesse sentido, acreditamos numa prática docente que possa incentivar leituras prazerosas, interdisciplinares e dialógicas de textos literários a partir da valorização e de uma observação atenta quanto aos ícones de comida nele manifestados. A carnavalização do comportamento docente permite-nos repensar currículos e práticas pedagógicas de modo a articular e, sobretudo, a valorizar a tematização contextualizada das culturas populares no âmbito da educação formal.

A seguir, buscaremos compreender a carnavalização da linguagem e da literatura sob a ótica bakhtiniana, a partir de alguns pressupostos teóricos que subsidiam tal concepção e a sua relação com o ensino de literatura no contexto da educação básica. 


\section{O ENSINO DE LITERATURA: DIÁLOGOS COM BAKHTIN E O CÍRCULO}

Mikhail Mikhailovich Bakhtin e seu Círculo de interlocutores, conhecido como o Círculo de Bakhtin, inauguraram no século XIX debates acerca da linguagem em contraposição às perspectivas formalistas presentes no cenário russo do século XX. Em um livro escrito pelo filósofo russo, em 1929, com o título Problemas das obras criativas de Dostoiévski e reeditado em 1963 sob o título de Problemas da poética de Dostoiévski no qual além de Bakhtin (2010) analisar as produções literárias de Fiódor Dostoiévski e destacar um novo conceito: o romance polifônico, o estudo da sátira menipéia para a compreensão das relações dialógicas em textos parodísticos, a presença do sério cômico em textos literários é também anunciada pelo estudioso russo.

Sabemos que as reflexões bakhtinianas sobre a linguagem e suas infinitas possibilidades privilegiaram o romance como objeto de estudo, especialmente a prosa do autor russo Fiodor Dostoiévski (1821-1881). O exame dos discursos no romance possibilitou ao pensador percorrer também os caminhos da análise das práticas de linguagem no dia a dia.

A “carnavalização" é um conceito de Bakhtin estruturado, primeiramente, no livro Problemas na Poética de Dostoiévski. Contudo, será na obra A Cultura Popular na Idade Média e no Renascimento: o contexto de François Rabelais, lançado em 1965, que a o interesse do filósofo russo pelas fontes da cultura popular e pelas imagens rabelaisianas, nas quais o caráter peculiar explica a resistência desse autor diante dos cânones e padrões estético-literários do século XIX, será evidenciado, de modo que o filósofo russo aprofundará o conceito a partir da análise das principais obras literárias do renascentista François Rabelais. Explorando princípios artísticos dos romances do escritor francês, o estudioso russo desenvolveu a teoria de uma cultura universal de humor popular.

Conforme Bakhtin (2008) o que se abolia, principalmente, durante o carnaval, era a hierarquia. Leis, proibições e restrições, padrões determinantes do sistema e da ordem cotidiana são suspensos durante o carnaval: revoga-se antes de tudo o sistema hierárquico e todas as formas determinadas pela desigualdade social hierárquica e por qualquer outra espécie de desigualdade entre os homens. O carnaval, bem como outros festejos populares, ocupa um lugar primordial na vida dos sujeitos medievais: esses folguedos ofereciam uma visão de mundo diferente da perspectiva séria e moralista difundida, sobretudo, pela Igreja e pela 
nobreza. Havia uma "dualidade do mundo" (Bakhtin, 2008, p. 5), que abarcava a ótica da cultura oficial consagrada por uma tradição religiosa e puritana e da cultura popular, com seus variados ritos e espetáculos configurados de forma cômica. As festividades que circulavam em torno da subversão cômica da ordem são características da cultura popular medieval responsável por potencializar um riso libertador, já que a

[...] teoria da cultura cômica popular medieval e do Renascimento abrange as formas da praça pública e da festa popular, as formas de ridicularização da verdade e do poder antigos com todo o seu sistema de mascaramentos (disfarces, mascaradas), de permutações hierárquicas (viradas do avesso), de destronamento e rebaixamentos. A relativização da verdade e do poder dominantes constitui um dos sentidos profundos do riso carnavalesco nas suas múltiplas manifestações; ao ridicularizar tudo o que se arroga de uma condição imutável, transcendente, definitiva, o carnaval celebra a mudança e a renovação do mundo (SOERENSEN, 2011, p. 323).

Todas as formas e símbolos da linguagem carnavalesca estão impregnados do lirismo da alternância e da mudança, da consciência da alegre relatividade das verdades e autoridades do poder. Avaliar o conceito de carnavalização, assim, é imprescindível para o entendimento de que a carnavalização da literatura é materializada na transposição da linguagem carnavalesca para a linguagem literária, impregnada de elementos próprios do universo festivo, por trazer em sua edificação "[...] o lirismo da alternância e da renovação, da consciência da alegre relatividade das verdades e autoridades no poder. Ela caracteriza-se, principalmente, pela lógica original das coisas "ao avesso", "ao contrário" [... (BAKHTIN, 2010, p.10). O carnaval perpassa a esfera artística do espetáculo teatral e situa-se nas fronteiras entre a arte e a vida; para o homem medieval, carnaval não era uma forma artística de espetáculo teatral, mas uma forma concreta - ainda que provisória - da própria vida, que não era simplesmente representada no palco, mas vivida enquanto durava o carnaval.

Tal visão ativa e libertadora da linguagem literária apresenta-nos também uma visão do mundo coerente e organizada, sedimentada pelo riso coletivo antagônico à seriedade e à rigidez da cultura oficial. Bakhtin reafirma o potencial da linguagem literária carnavalizada em sua perspectiva de rompimento com as relações hierárquicas ainda existentes na visão formalista do texto ficcional: 
O carnaval criou toda uma linguagem de formas concretosensoriais simbólicas, entre grandes e complexas ações de massas e gestos carnavalescos. Essa linguagem exprime de maneira diversificada e, pode-se dizer, bem articulada (como toda linguagem) uma cosmovisão carnavalesca una (porém complexa), que lhe penetra todas as formas. Tal linguagem não pode ser traduzida com o menor grau de plenitude e adequação para a linguagem verbal, especialmente para a linguagem dos conceitos abstratos, no entanto é suscetível de certa transposição para a linguagem cognata, por caráter concretamente sensorial, das imagens artísticas, ou seja, para a linguagem da literatura. É essa transposição do carnaval para a linguagem da literatura que chamamos carnavalização da literatura (BAKHTIN, 2010, p. 124).

$\mathrm{O}$ aspecto regenerador e fecundo do riso presentes em produções literárias, pois, poderá trazer de forma construtiva - para o cenário das práticas de leitura diálogos potentes com a cultura popular em oposição à cultura oficial ainda tão excludente e impositiva, bem como incentivar a revisão de estruturas rígidas no universo ficcional, por meio da subversão das regras e das escolhas, para além dos cânones oficiais.

Ao analisar essas perspectivas teóricas no contexto de produção e de comportamento docentes, torna-se viável prospectar uma ruptura para o ensino de estrutura tradicional; o professor, ciente da realidade em que se insere e consciente dos insucessos no estímulo a leituras críticas que permeiam as práticas comuns, precisa questionar e dissolver normativas padrões, a fim de estabelecer uma verdadeira formação engajada de leitores de palavras e do mundo. A carnavalização do comportamento docente, logo, permite-nos repensar currículos e práticas pedagógicas de modo a articular a valorização e a tematização contextualizada das culturas populares no âmbito da educação formal. Estabelecer essa postura docente carnavalizada permite, ainda, maior dialogismo e alteridade nas práticas educativas, uma vez que os discentes e os docentes poderão identificar mais vozes e valores manifestados nos discursos das leituras literárias.

Valorizar o estudo de textos literários que dialoguem ou, minimamente, referenciem o ato alimentar, é uma válida alternativa para estabelecer práxis docentes próximas ao conceito bakhtiniano de carnavalização; assim, estudar Dona Flor e seus dois maridos sob a ótica da carnavalização e da representação social dos simbolismos alimentares permite-nos refletir a respeito da relação entre os saberes da alimentação e o gênero feminino, bem como possibilita pensar a 
inserção da mulher no mercado de trabalho no Brasil de 1960 - diferente do que insiste o tradicionalismo escolar para o ensino de literatura ao difundir, acima de qualquer leitura crítica, uma biografia a respeito do autor. Todavia, ainda é possível subverter certa lógica sem totalmente eliminá-la: caracterizar Jorge Amado como escritor baiano e revisitar seu acervo literário para degustar as receitas típicas da cultura nordestina favorece uma análise sobre a formação da identidade social daquela região; quais seriam as influências socio-históricas para a popularização do vatapá na Bahia e por que ele é destacado em suas narrativas, por exemplo? Nesses mesmos moldes de análise carnavalizada, acessar a produção de Monteiro Lobato para crianças capacita questionar por que uma personagem negra é relacionada a saberes informais e uma personagem branca é associada ao saber formal, no Brasil de 1930, por exemplo.

Acreditamos que o ensino de literatura pode favorecer a descoberta de valores de mundo por meio de uma leitura subjetiva, individual e experiencial, mas que potencialize ainda um acesso de forma mais crítica às experiências concretas vividas em coletividade. É função do professor incentivar e propiciar leituras diversas dos textos literários para que o aluno venha tornar, como sua, a cultura que foi produzida pela humanidade, por meio de uma educação que ofereça suporte para que o homem atinja a transformação social diante do conhecimento da cultura amontoada pelo coletivo, pois a escola além de ser incentivadora de conhecimentos baseados em conteúdo é também uma instituição desencadeadora de processos sociais de comunicação e de identidade dos seres. Com isso, pode-se apreender a atuação carnavalizada como possibilidade de implementar a mudança necessária de paradigmas para uma educação escolar efetivamente mais festiva e prazerosa, ainda que profundamente crítica no que tange ao diálogo com a realidade.

\section{PROPOSTAS PEDAGÓGICAS: NOVOS DIÁLOGOS NA FORMAÇÃO DOCENTE}

Baseados nos pressupostos teóricos e práticos que relacionam gastronomia, carnavalização e formação docente, apresentamos, a seguir, uma proposta de formação de professores para potencializar reflexões críticas às práticas pedagógicas a respeito do ensino de literatura em sala de aula. Por entender que comida e literatura potencializam diversos recortes temáticos para pensar a 
atuação docente, vamos, aqui, recorrer à noção de "receita" enquanto valor simbológico para conduzir uma difusão carnavalizada de ensino de literatura.

\section{Quadro 1 - Quadro com a exposição do título de encontro temáticos e seus objetivos norteadores}

\begin{tabular}{|c|c|}
\hline Título do encontro temático & Objetivos norteadores \\
\hline $\begin{array}{l}\text { Receitas docentes: a injunção nos } \\
\text { cadernos de literatura }\end{array}$ & $\begin{array}{l}\text { Dialogar sobre práticas docentes para a } \\
\text { leitura de textos literários, além de } \\
\text { problematizar as fórmulas injuntivas e } \\
\text { acríticas no acesso às obras literárias. }\end{array}$ \\
\hline
\end{tabular}

Fonte: elaborado pelo autor.

Entende-se, por receita, um gênero textual da esfera discursiva injuntiva, fundamentado em modos imperativos de orientação para que se possa alcançar determinado efeito. Ao problematizar uma condução docente injuntiva e, portanto, imperativa no ensino de literatura, problematizam-se os modelos tradicionais pouco dialógicos para o estimulo a leituras de obras literárias. Embora a ideia de receita seja uma metaforização para essa condução injuntiva da prática docente, não se pode negar que o trabalho do professor também com a literatura em muito é condicionado por sugestões didáticas popularizadas em manuais pedagógicos, por diversas vezes articulados em materiais didáticos.

Essa metodologia injuntiva aplicada ao fazer docente capacita uma difusão limitada e pouco crítica dos simbolismos literários e suas possíveis interpretações, de modo a criar práticas pouco alinhadas a uma compreensão mais ampla da realidade. Questionar tal premissa é permitir que novas experiências originem diferentes receitas para que possamos, assim, constituir um novo repertório de trabalho crítico no ensino de literatura em sala de aula.

A injunção, nesse contexto docente, impede que as vozes discentes emerjam nas práticas de leitura, negando, pois, a garantia da alteridade, da consideração do outro e da diversidade de cada mundo particular no diálogo com os livros. A recorrência dessas práticas autoritárias na escola cria um distanciamento cada vez maior entre a leitura e a realidade concreta, entre a arte e a vida, entre a escola e a formação de sujeitos críticos que precisam fazer do encontro com a literatura também uma forma de compreender melhor sua posição no mundo. 
A seguir, apresentamos uma sugestão de planejamento detalhado para a condução desse processo formativo, sob a ótica da interlocução entre o universo da gastronomia e uma perspectiva carnavalizada da literatura nos encontros docentes. Para caracterizar a temática, procuramos estabelecer diálogo contínuo entre as terminologias relacionadas à alimentação com a organização temporal para os momentos do encontro, expostos a seguir em nossos quadros expositivos.

Quadro 2 - Quando da exposição das sensibilizações iniciais do encontro formativo

\begin{tabular}{|c|l|}
\hline \multirow{5}{*}{ Aperitivo } & $\begin{array}{l}\text { Pensar a leitura crítica de literatura requer que } \\
\text { estejamos disponíveis para experimentar novos } \\
\text { sabores produzidos pelos textos. Em prol de } \\
\text { despertar o apetite literário dos alunos, é possível que } \\
\text { o professor tenha, primeiro, que lhes oferecer } \\
\text { pela apresentação dos do encontro } \\
\text { objetivos) }\end{array}$ \\
típicas. Novas ocasiões, contudo, trazem novas \\
expectativas e, assim, novas comidas potencializam \\
também diferentes experiências. Eis, aí, uma grande \\
questão: para que a lógica seja correspondida, é \\
preciso ter um repertório apurado e atualizado de \\
receitas. Insistir em injunções que não resultam em \\
resultados apetitosos pode ser fatalmente indigesto. \\
Na tarefa de produzir incentivo a leituras críticas, os \\
textos literários potencializam novos processos ao \\
trabalho e à preparação docente. Vamos trocar \\
receitas?
\end{tabular}

Fonte: elaborado pelo autor.

$\mathrm{Na}$ primeira sessão, intitulada "aperitivos", poderão ser estimuladas reflexões iniciais acerca da condução docente da literatura em sala de aula, antes das observações conceituais mais consistentes. Tais análises podem ser promovidas, por exemplo, por meio de rodas de conversas. Uma vez concretizadas, essas primeiras reflexões potencializarão avaliar outros paradigmas, apresentados a seguir: 
Quadro 3 - Quadro de sugestões provocativas para encontro formativo

\begin{tabular}{|c|l|}
\hline Couvert & $\begin{array}{l}\text { Enquanto não conceituamos o tema do nosso } \\
\text { encontro, deguste essas provocações: }\end{array}$ \\
(Provocações) & $\begin{array}{l}\text { Pode um único sabor agradar a todos em uma } \\
\text { refeição? Existe receita de atuação docente aberta a } \\
\text { adaptações a fim de que todos apreciem o resultado? }\end{array}$ \\
\hline
\end{tabular}

Fonte: elaborado pelo autor.

Na próxima sessão, a de "couvert", poderão ser sugeridas observações provocativas acerca da perspectiva de "receitas docentes"; nesse contexto, prevalece o intuito de questionar proposições injuntivas em sala de aula para o ensino de literatura. Enquanto em "aperitivo" o objetivo era o de promover a descompressão das atividades rotineiras e situar o sujeito-participante da formação nos propósitos da dinâmica, em “couvert” pretende-se já estimular um pensamento crítico acerca da atuação docente, anterior a noções conceituais formais relacionadas à tríade gastronomia-carnavalização-literatura. Verifica-se, já nas terminologias e na dinâmica de organização do processo formativo, a possibilidade de subverter padrões de contextos formais como estratégia para vislumbrar uma interação diferente e eventualmente mais atrativa e mais prazerosa.

Na sequência, a primeira formalização conceitual é sugerida em uma sessão intitulada "entrada", cujo propósito, observa-se abaixo:

Quadro 4 - Quadro de sugestões conceituais relacionadas à gastronomia para encontro formativo

\begin{tabular}{|c|l|}
\hline Entrada & $\begin{array}{l}\text { Referência aos estudos de Savarin acerca da } \\
\text { alimentação enquanto ciência e de Massimo }\end{array}$ \\
(Conceitos & $\begin{array}{l}\text { Montanari a respeito dos simbolismos socioculturais } \\
\text { gerpetrados pela comida. }\end{array}$ \\
\hline
\end{tabular}

Fonte: elaborado pelo autor.

Nesse contexto, sugere-se iniciar o percurso de conceitos formais pela ciência que estrutura o banquete; assim, referências formais à gastronomia podem ser estabelecidas como modo de enaltecer a representatividade social exercida pela comida a partir dos simbolismos nela envolvidos. Caberia, nesse propósito, 
priorizar as análises desenvolvidas por Massimo Montanari, enquanto pesquisador contemporâneo, por entender a alimentação em perspectiva sociocultural. Devidamente situados e alimentados com os primeiros estímulos para digerir a relação entre comida e sociedade, passa-se para o serviço de bebida.

Quadro 5 - Quadro de sugestões conceituais relacionadas à carnavalização para encontro formativo

\begin{tabular}{|c|l|}
\hline Bebida & $\begin{array}{l}\text { Referências introdutórias à origem do conceito de } \\
\text { carnavalização, desenvolvido por Mikhail Bakhtin. }\end{array}$ \\
\hline
\end{tabular}

Fonte: elaborado pelo autor.

Nesse momento da formação, noções que apresentem a carnavalização enquanto referencial teórico para estudos da linguagem literária serão priorizadas. O que se pretende, contudo, é avaliar a cosmovisão carnavalesca enquanto estrutura potente também para a atuação do professor de literatura. Beber dessa notação conceitual possibilita que o sujeito-participante da formação, a essa altura, esteja mais disponível para promover e propagar leituras críticas nas suas práticas em sala de aula. Com isso, servimo-nos do prato principal:

Quadro 6 - Quadro com a exposição de texto literário para encontro formativo

\begin{tabular}{|c|l|}
\hline $\begin{array}{c}\text { Prato Principal } \\
\text { (Corpus literário) }\end{array}$ & Texto “O Prazer de Ler”, de Rubem Alves. \\
\hline
\end{tabular}

Fonte: elaborado pelo autor.

Na construção de "O Prazer de Ler", Rubem Alves dinamiza uma reflexão acerca do estímulo ao apetite literário por meio de correlação com expressões características do universo gastronômico. Conduzir a leitura coletiva dessa crônica tem como objetivo vislumbrar uma compreensão ainda mais efetiva de que a leitura literária, tal como a comida, é prática dotada de aspectos simbológicos de uma realidade social. A leitura desse corpus literário tende a favorecer, também, a interação conceitual proposta para esse encontro formativo, a seguir evidenciada finalmente sob o título de "harmonização": 
Quadro 7 - Quadro de questões para debate em encontro formativo

\begin{tabular}{|c|c|}
\hline $\begin{array}{c}\text { Harmonização } \\
\text { (Gastronomia, } \\
\text { carnavalização e } \\
\text { literatura em sala de } \\
\text { aula) }\end{array}$ & $\begin{array}{l}\text { Questões para dialogar: } \\
\text { - } \quad \text { Que receitas são sistematicamente impostas } \\
\text { sobre a leitura de textos literários em contexto } \\
\text { escolar - via práticas tradicionais, materiais } \\
\text { didáticos e afins? } \\
\text { - } \quad \text { Que práticas têm despertado o interesse social } \\
\text { pelos simbolismos associados à comida? De que } \\
\text { modo essas práticas poderiam ser aplicadas ao } \\
\text { ensino de literatura ou à leitura de textos } \\
\text { literários? } \\
\text { - Como o professor de português pode } \\
\text { responsavelmente subverter as receitas } \\
\text { sistematizadas e criar novas, a partir de sua } \\
\text { atuacão? }\end{array}$ \\
\hline
\end{tabular}

Fonte: elaborado pelo autor.

Nessa etapa da interação formativa, pretende-se evidenciar como os conceitos anteriormente discutidos (embora oriundos de naturezas distintas) podem ser aplicados para justificar e fundamentar a atuação docente. Estruturado por perguntas abertas, os tópicos permitem uma reflexão ampla acerca de novos paradigmas para o ensino de literatura na escola. Contudo, a cristalização de novos fazeres docentes pretende estabelecer a etapa seguinte da formação, a qual intitulamos como "sobremesa":

Quadro 8 - Quadro com apresentação de novas possibilidades de atuação docente em encontro formativo

\begin{tabular}{|c|c|}
\hline \multirow{2}{*}{ Sobremesa } & $-\begin{array}{l}\text { "Marmelada de banana, bananada de goiaba, } \\
\text { goiabada de marmelo". O verso que subverte a } \\
\text { compreensão de receitas clássicas da doçaria } \\
\text { nacional e inicia a canção de Gilberto Gil para a } \\
\text { (Repensar de práticas } \\
\text { docentes) }\end{array}$ \\
& $\begin{array}{l}\text { ersão televisiva da obra - livremente inspirada } \\
\text { Pica-Pau Amarelo" é um símbolo da cultura } \\
\text { nacional que identifica e assimila sua produção } \\
\text { literária infantil ao longo de diversas gerações. } \\
\text { Tanto as composições escritas quanto as versões }\end{array}$ \\
\hline
\end{tabular}




\begin{tabular}{|l|l|}
\hline audiovisuais evidenciam curiosa relação entre \\
personagens, enredos e simbolismos da \\
alimentação. Quindim, por exemplo, é - além do \\
nome de um tradicional doce da cultura \\
portuguesa (muito consumido em terras \\
brasileiras) - o rinoceronte-personagem adotado \\
pelos habitantes do sítio, após fugir de um circo \\
onde sofria extremos maus tratos. Visconde de \\
Sabugosa é o nome dado ao boneco feito de \\
sabugo de milho, cuja sabedoria intelectual \\
obteve através dos livros observados na biblioteca \\
de Dona Benta. Falando nela, é válido destacar \\
um aspecto que criou uma visão social curiosa a \\
seu respeito no imaginário popular: nas narrativas \\
que permeiam o Sítio, deliciosas preparações são \\
elaboradas na cozinha da anciã; quase nenhuma, \\
entretanto, é por ela produzida. Embora o \\
trabalho de cozinhar no sítio seja \\
majoritariamente exercido pela negra conhecida \\
como Tia Nastácia, Dona Benta é que \\
conquistou a referência dos saberes formais \\
relacionados à culinária - vide exploração pelo \\
mercado editorial em livros de receita e, \\
posteriormente, produtos da indústria \\
alimentícia. Que valores socioculturais são \\
passíveis de estudo a partir dessa constatação - e \\
outras admissíveis - em práticas de leitura crítica \\
do texto literário? Como o professor pode \\
desenvolver sua atuação a partir da análise desses \\
símbolos, a fim de despertar o interesse de \\
leitores em fase escolar? Que novas dinâmicas \\
de aula podem formular boas receitas para o \\
trabalho com textos literários em sala de aula? \\
\hline auta
\end{tabular}

Fonte: elaborado pelo autor.

Aqui, o encontro formativo pretende alcançar seu ápice: os sujeitosparticipantes, munidos dessa sensibilização estruturada pela relação entre comida e literatura, poderão revisitar leituras para verificar as simbologias alimentares 
nelas presentes e, assim, consolidar uma nova perspectiva de se trabalhar com obras literárias em sala de aula. Por ocasião do tempo, eventualmente, algumas ideias e/ou propostas não conseguirão ser aprimoradas. Nesse caso, uma nova sessão pode ser articulada em prol de motivar a continuidade desses estudos.

Quadro 9 - Quadro com sugestões de leitura em encontro formativo

\begin{tabular}{|c|l|}
\hline \multirow{2}{*}{ Aceita um café? } & $\begin{array}{l}\text { À mesa com Monteiro Lobato (de Marcia Camargos } \\
\text { e Vladimir Sacchetta; Editora SENAC, 2008) }\end{array}$ \\
Márcia Camargos e Vladimir Sacchetta são \\
renomados pesquisadores lobatinos e, para esta \\
publicação, contaram com consultoria especializada \\
na culinária do Vale do Paraíba, a terra natal de \\
Lobato, ora em relação à culinária brasileira, que bem \\
se revela quer polêmicas ideológicas travadas com os \\
modernistas da Semana de 22, quer em hábitos \\
alimentares de sua mesa, no dia-a-dia, ou de seus \\
personagens, na sua ficção.
\end{tabular}

Fonte: elaborado pelo autor.

Para finalizar a sugestão de estudo - compreendendo que o diálogo não se finda - sugestões de leitura podem ser articuladas em uma sessão exclusiva para que os sujeitos envolvidos na formação possivelmente tomem notas de outros potenciais acessos a serem feitos no período pós-encontro; são as leituras estabelecendo inter-relações e interconexões. Assim pretendemos que também ocorram em sala de aula novas conexões entre saberes e sabores potencializando leituras críticas no processo de formação do leitor de literatura.

\section{CONSIDERAÇÕES PARA NOVOS DIÁLOGOS}

Sob essas perspectivas a respeito de ler e de alimentar-se, admite-se que, ao comer, o leitor reconhece e dialoga com inúmeros valores e ideias, bem como, ao ler, possibilidades imaginativas e críticas acerca de diversas realidades de mundo são degustadas pelos sujeitos envolvidos na ação. 
Promover estudos relacionados à gastronomia potencializa, portanto, explorar inclusive as noções culturais da alimentação manifestadas em diversos saberes. Ao avançar nos entendimentos de que a gastronomia é um resultado de potentes arranjos sociais, buscamos oferecer um panorama mais promissor e valorizado de suas representações. Sem dúvida, a comida é espaço amplo para as representações. A exposição da comida em obras literárias potencializa variadas leituras críticas. A arte literária exige olhares mais atentos e apurados. A gastronomia, enquanto ciência, legitima o potencial de representação de valores sociais exercidos pela comida. É preciso apurar os sentidos para saborear novas visões sobre textos e também sobre a sociedade.

A atuação carnavalizada do professor de literatura em muito pode contribuir para favorecer essas leituras críticas da comida, do livro e dos valores sociais neles perpetrados, visto que o ensino de Literatura nessa abordagem pressupõe o diálogo entre as culturas: erudita e popular, origina uma desestabilização do discurso monológico e impositivo que permeia muitas das orientações docentes nos documentos oficiais da área educacional e ao dessacralizar a literatura na escola nos remete a outro princípio da carnavalização bakhtiniana, a zona do contato familiar que aproxima ao máximo o mundo do homem e o homem do homem.

Ainda nessa perspectiva, entendemos que as práticas de leitura precisam garantir a alteridade, a consideração do outro e a compreensão da diversidade de cada mundo particular no diálogo com os livros. Talvez esse artigo se caracterize mais como aperitivo de um delicioso banquete que poderá ser preparado - e para o qual, convenhamos, nunca haverá apenas um livro de receitas.

\section{REFERÊNCIAS}

ALVES, Rubem. Entre a ciência e a sapiência: o dilema da educação. São Paulo: Edições Loyola, 2007. 152p.

BAKHTIN, Mikhail M. A cultura popular na Idade Média e no Renascimento: o contexto de François Rabelais. São Paulo: Hucitec, 2008. 428p.

BAKHTIN, Mikhail M. A cultura popular na Idade Média e no Renascimento: o contexto de François Rabelais. 7 ed. Brasília: Editora Universidade de Brasília, 2010 . 
BAKHTIN, Mikhail M. Problemas da poética de Dostoiévski. Trad. Paulo Bezerra. 5 ed. rev. Rio de Janeiro: Forense Universitária, 2010.

BARTHES, Roland. O prazer do texto. São Paulo: Editora Perspectiva, 1999. 80p.

CRUSOÉ, Nilma Margarida de Castro. A teoria das representações sociais em Moscovici e sua importância para a pesquisa em educação. APRENDER - Cad. de Filosofia e Psic. da Educação. Vitória da Conquista, Ano II, n. 2, p. 105-114, 2004 .

DÓRIA, Carlos Alberto. Estrelas no céu da boca: escritos sobre culinária e gastronomia. São Paulo: Senac, 2006. 268p.

DÓRIA, Carlos Alberto. A cozinha materialista. São Paulo: Senac, 2009. 264p.

MONTANARI, Massimo (Org.). O mundo na cozinha: história, identidade, trocas. São Paulo: Senac São Paulo, 2009. 256p.

SANTOS, C. R. A. dos. A alimentação e o seu lugar na História. Os tempos da memória gustativa. História: Questões \& Debates, v. 42, 2005, p.11-31.

SAVARIN, Brillat. A fisiologia do gosto. São Paulo: Companhia da Letras, 1995. 352p.

SOERENSEN, Claudiana. A carnavalização e o riso segundo Mikhail Bakhtin. Travessias, Cascavel, v. 5, n. 1, maio 2017, p.318-328.

Recebido em 11 de junho de 2020 Aprovado em 31 de agosto de 2020 